\title{
EDUCAÇÃO PROTESTANTE NORTE AMERICANA E PROCESSO CIVILIZADOR: CONTRIBUIÇÕES PARA O DEBATE
}

\author{
Protestant North American education and the civilizing process: contributions \\ to the debate
}

Educación protestante Norteamericana y proceso civilizador: aportaciones al debate

Cesar Romero Amaral Vieira ${ }^{1}$

Luiz Cândido Martins ${ }^{2}$

Magda Sarat ${ }^{3}$

\begin{abstract}
Resumo
O Brasil do final do século XIX e início do século XX recebeu um grande número de estrangeiros imbuídos de projetos civilizatórios e republicanos, focados em experiências educacionais, especialmente na fundação de colégios e instituições. Neste artigo, pretende-se analisar alguns conceitos sociológicos de Norbert Elias sobre Processos Civilizadores para compreender essa onda civilizatória, em diálogo com os escritos de Alexis de Tocqueville. Considera-se para isto, o modelo educacional norte-americano e protestante que esteve presente no Brasil e, nas concepções dos grupos que aqui chegaram. Empiricamente utilizar-se-á dados de pesquisas acerca da história da educação protestante, realizadas a partir de fontes orais e documentais. Portanto, destaca-se que o modelo educacional norte americano fez parte do ideal civilizatório propalado e aceito, não somente nos discursos, mas nas práticas recorrentes do período -a república em construção- na qual estavam expressas as concepções e propostas de mudanças educacionais e sociais com o intuito de levar o país ao patamar de nação civilizada.
\end{abstract}

PALAVRAS-CHAVE: História da Educação Protestante. Educação Norte-Americana. Norbert Elias.

\begin{abstract}
In the late 19th and early 20th centuries, Brazil received a large number of foreigners imbued with civilizational and republican projects, focused on educational experiences, especially in the founding of schools and institutions. In this article, one aims to analyze some sociological concepts of Norbert Elias on Civilizing Processes to understand this civilizing wave, in a dialogue with the writings of Alexis de Tocqueville. For this purpose, the US and Protestant educational model that was present in Brazil and in the conceptions of the groups that arrived here is considered. Empirically, research data on the history of Protestant education from oral and documentary sources will be used.
\end{abstract}

\footnotetext{
${ }^{1}$ Doutor em Educação pela Universidade Metodista de Piracicaba (UNIMEP) e doutor em Ciências da Religião pela Universidade Metodista de São Paulo. Docente do Programa de pós-graduação em Educação da Universidade Metodista de Piracicaba (UNIMEP). Endereço: Rodovia do Açúcar, km 156, Piracicaba, SP, Brasil. E-mail: crvieira@ unimep.br

${ }^{2}$ Doutor em Educação pela Universidade Metodista de Piracicaba (UNIMEP). Docente na Faculdade de Administração, Ciências Contábeis e Economia - FACE/UFGD. Departamento de Agronegócio. Dourados, MS, Brasil. Endereço: Rodovia Dourados - Itahum, km 12. Cidade Universitária. CEP 79804-970. Dourados, MS, Brasil. E-mail: luizmartins@ufgd.edu.br

${ }^{3}$ Doutora em Educação pela Universidade Metodista de Piracicaba (UNIMEP). Docente do Programa de pós-graduação em Educação da Universidade Federal Da Grande Dourados UFGD. Dourados, MS, Brasil. Endereço: Rodovia Dourados - Itahum, km 12. Cidade Universitária. CEP 79804-970. Dourados, MS, Brasil. E-mail: magdasaratufgd@ hotmail.com
} 
Therefore, it is important to note that the US educational model was part of the civilizing ideal promoted and accepted not only in the discourses, but also in the recurring practices of the period the republic under construction - in which the conceptions and proposals of educational and social changes were expressed with the intention of taking the country to the level of a civilized nation.

KEYWORDS: History of Protestant Education. North American Education. Norbert Elias

\section{Resumen}

El Brasil de finales del siglo XIX y principios del XX recibió un gran número de extranjeros imbuidos de proyectos civilizatorios y republicanos, enfocados en experiencias educativas, especialmente en la fundación de colegios e instituciones. En este artículo, se pretende analizar algunos conceptos sociológicos de Norbert Elias respecto a los Procesos Civilizadores, en diálogo con los escritos de Alexis de Tocqueville, con el objetivo de comprender dicha ola civilizatoria. Para el presente estudio se toma en consideración el modelo educativo norteamericano y protestante llevado a cabo en el Brasil y, las concepciones de los grupos que aquí llegaron. También se utiliza datos empíricos de investigaciones acerca de la historia de la educación protestante, recolectados desde fuentes orales y documentales. Así, se destaca que el modelo educativo norteamericano formó parte del ideal civilizatorio propalado y aceptado, tanto en los discursos como en las prácticas recurrentes del período - la república en construcción - en el cual se expresaban las concepciones y propuestas de cambios educativos y sociales con el propósito de elevar la categoría del país a nación civilizada.

PALABRAS CLAVE: Historia de la Educación Protestante. Educación Norteamericana. Norbert Elias.

\section{INTRODUÇÃO}

"Fui professora da Escola Dominical, ativa até o ano retrasado, vou fazer 90 anos em setembro. Todas as manhãs de domingo eu vou a igreja, dominicalmente estou lá (...)”.

D. Jair (90 anos)

Pela epígrafe acima é possível perceber como a educação e a religião de origem protestante obtiveram êxito na formação dos indivíduos que por elas foram alcançados por meio de seus colégios, igrejas e pela ação formativa proposta pelas escolas dominicais ${ }^{4}$, instituição responsável pela popularização de uma cultura cívica entre os setores menos favorecidos da sociedade. De modo enfático - em uma entrevista realizada para uma pesquisa anterior ${ }^{5}$ - a professora Jair de Araújo Lopes, à época com 89 anos, iniciou sua fala ressaltando ser "de família plenamente metodista" $\mathrm{e}$, a partir daí passou a relatar, por este viés identitário, toda sua concepção de educação, trabalho docente e infância. O que de imediato induz a pensar na pesquisa de Max Weber sobre a importância da filiação religiosa na formação dos Estados Unidos. Weber descreve que durante o período colonial "a cidadania plena na congregação religiosa era condição preliminar para a cidadania plena no estado" (WEBER, 1982, 356). Dizer-se protestante era, pois, considerado uma garantia

\footnotetext{
${ }^{4} \mathrm{O}$ movimento das escolas dominicais surgiu na Inglaterra na segunda metade do século XVIII com o objetivo de evangelizar e educar crianças que ficavam largadas nas ruas das cidades operárias sem quaisquer atividades aos domingos, a mercê dos vícios, da violência e do crime.

${ }^{5}$ OLIVEIRA (1999) nas referências deste artigo.

${ }^{6}$ Optamos em deixar os fragmentos das fontes orais em itálico como forma de dar visibilidade.
} 
de qualidades morais e políticas. Tal aspecto fica marcante na entrevista com dona Jair, como era conhecida, pois nela exalta sua formação, bem como, o reconhecimento e a valorização das experiências de uma educação adquirida tanto no âmbito de uma comunidade protestante como nos bancos de seus colégios - no caso aqui relatado, da denominação metodista, da qual fez parte por toda a sua vida: "Papai queria muito que a gente estudasse nos nossos colégios! Eu fui para o IMERP (Instituto Metodista de Ribeirão Preto). Em Belo Horizonte para o Izabella Hendrix. Estudei no Bennett (Instituto Metodista Bennett) no Rio de Janeiro. Fiz o magistério no Bennett” (D. Jair, 90 anos).

A história da inserção do protestantismo norte-americano a partir da instalação de seus colégios há muito vem sendo investigada no âmbito da história da educação brasileira $^{7}$. Embora não se trata de uma discussão nova, sua visibilidade ainda é bastante tênue em alguns períodos históricos. Neste artigo nos remetemos ao aspecto específico da sua inserção no Brasil no final do século XIX, para tentar compreender como esta presença favoreceu a determinados setores da sociedade brasileira desejosos de pôr em movimento um projeto liberal de civilidade. Para isto, procuraremos lançar fechos de luzes no significado do modelo educacional norte-americano, destacando seus propósitos "republicanos" e "civilizadores", do qual os missionários protestantes foram os seus principais agentes atendendo a um apelo expansionista, de uma nação que se pensava portadora de um projeto civilizador que como um poderoso farol iluminaria os rincões mais obscuros do mundo.

É possível afirmar que dentre as concepções que os alimentavam estava a ideia do Destino Manifesto. Pacto basilar na história da formação da nação norte-americana firmado pelos pioneiros puritanos que atravessaram o Atlântico em direção ao novo mundo, em novembro de 1620, e que tem como centralidade a firme convicção de que eles, a exemplo dos israelitas que cruzaram o Mar Vermelho, seriam o novo povo escolhido por Deus para a missão de levar ao mundo os ideais de uma alta sociedade cristã, não por privilégios concedidos, mas como um dever a ser cumprido. Esta visão mítica do mundo, fortalecida pelo puritanismo inglês, cultivou nos Estados Unidos a ideia de que a "a religião e a civilização estavam unidas na visão da América Cristã e que a ação de Deus no mundo se verificava por intermédio de povos especialmente escolhidos" (MESQUIDA, 1994, p. 103), dando suporte a justificativa para o programa expansionista desenvolvido principalmente depois da independência de suas colônias.

A percepção messiânica dos povos anglo-saxões, estava firmemente fundada na tradição cristã rumo à perfeição e, indicava uma esperança escatológica que unia os protestantes de diferentes ramos teológicos e doutrinários. Certos de sua "missão salvadora" sob sua responsabilidade se entregaram ao trabalho de difundir um "cristianismo republicano" e a contribuir com as lutas por reformas sociais, principalmente nos países latino americanos em transição, a partir da formação de uma população religiosa, crente, livre e letrada que obedeceria às leis da sociedade civil. Segundo Mesquida, "é neste quadro ideológico que encontramos o expansionismo transcontinental das denominações missionárias protestantes norte americanas" (MESQUIDA, 2016, p. 190).

Neste breve artigo, nos propomos, a partir da emblemática questão posta por Alexis de Tocqueville, a refletir sobre o papel que a religião e a educação significaram para a formação da nação americana. Ainda que saibamos que Tocqueville não tenha dedicado

\footnotetext{
${ }^{7}$ Sobre o tema ver o livro Contribuições do protestantismo... nas referências deste artigo.
} 
uma discussão sistemática sobre a educação norte-americana vale aqui refletir, mediado por seus escritos, como tais instituições se expandiram passando a fazer parte fundamental de um projeto civilizatório, via a transposição de igrejas e instituições educativas erguidas em diversos países. Projeto, que de acordo com o pensamento de Norbert Elias, tinha como propósito civilizar os povos, os costumes, os comportamentos, as formas de relacionar-se e imprimir novos modos de formação social.

Com o fito de responder algumas questões postas, trabalharemos, neste artigo, a partir de dois focos principais: primeiro dando ênfase na organização do protestantismo histórico e de seu projeto expansionista, a partir dos escritos de Alexis de Tocquevile na obra A Democracia na América (2005), publicada pela primeira vez na França em 1835, tomando-a como um estudo clássico que, além dos aspectos sócio políticos, dá destaque para religião e a educação escolar na formação cívica dos cidadãos norte-americanos. Embora os escritos de Tocqueville sejam cheios de ambiguidades ora destacando os valores universalizantes da democracia norte-americana em relação à Europa, ora advertindo sobre a importância de se guardar certos aspectos da tradição europeia em relação ao despotismo democrático norte-americano, não se pode esquecer de que as teorias de Tocqueville foram amplamente divulgadas no século XIX, e de acordo com Vianna Moog (2000, p. 21) elas contribuíram para transformar as nascentes constituições latino americanas em verdadeiras paráfrases da constituição norte-americana, tornando-se parâmetros de progresso, democracia e civilização (VIEIRA, 2006, p. 98). Em segundo lugar, tentaremos compreender este projeto expansionista a partir do diálogo com o pensamento de Norbert Elias e suas teorias dos processos civilizadores nas obras, Processo civilizador: uma história dos costumes (1994) e Processo Civilizador: formação do estado e civilização (1993). Nosso intuito é que esta reflexão contribua com o estudo da história da educação protestante no Brasil indicando novas perspectivas de análise à medida que tangenciamos às principais características da formação e organização do modelo educacional norte-americano, investigados e analisados à luz das teorias dos processos civilizadores de Norbert Elias.

\section{Religião e Educação na constituição do pensamento americano}

Antes de nos aprofundarmos na reflexão, é importante destacar que aqui falamos de um tipo de protestantismo denominado na historiografia religiosa brasileira de protestantismo missionário ou de missão (Cf. MENDONÇA, 2008), pois eram portadores de estratégias de penetração organizadas por sociedades missionárias que abrangiam tanto o campo estritamente religioso como o educativo de um modo geral, como bem observou Jean-Pierre Bastian em Protestantismos y modernidad latino-americana (1994). Originários do movimento de expansão missionária norte-americano, iniciado no alvorecer do século XIX, representantes das sociedades metodistas, presbiterianas, batistas e congregacionais chegaram ao Brasil com propósitos idênticos de evangelizar e educar a nação de acordo com os ideais de uma civilização cristã, moldada nos princípios norteamericanos $^{8}$ (VIEIRA, 2016, p. 135). A ata constitutiva da primeira sociedade missionária

\footnotetext{
8 A ata constitutiva da primeira sociedade missionária metodista registra que "estas associações foram concebidas para difundir os benefícios da educação e do cristianismo, para promover e sustentar escolas missionárias e missões cristãs nos Estados Unidos, em todo o continente americano e nos países estrangeiros", de acordo com o 54th Annual Report for the Missionary Society of the Methodisth Episcopal Church for the year 1873, New York, 1873, p 10, 12 e 14 (Apud BASTIAN, 1994, p. 106).
} 
metodista registra textualmente que estas sociedades missionárias foram concebidas para "difundir os benefícios da educação e do cristianismo, para promover e sustentar escolas missionárias e missões cristãs nos Estados Unidos, em todo o continente americano e nos países estrangeiros", de acordo com o 54th Annual Report for the Missionary Society of the Methodisth Episcopal Church for the year 1873, New York (Apud BASTIAN, 1994, p. 106). Visto a partir desta perspectiva, a educação seria, pois, utilizada como veículo privilegiado de propaganda indireta, cujo objetivo principal, era a penetração do protestantismo no continente americano, daí o seu aspecto proselitista. De acordo com Bastian, "o projeto escolar permitia difundir, fora do recinto do templo e da comunidade protestante, valores religiosos e políticos democráticos, assim como propor uma base moral e religiosa para a futura democracia liberal" (BASTIAN, 1994, p. 129).

Mendonça (1984), um dos mais respeitados pesquisadores do protestantismo brasileiro, também percebe na educação um forte componente da estratégia missionária na implantação do protestantismo no Brasil e na América Latina. Nestes países, as empresas missionárias, como bem classificou, foram enviadas com a dupla tarefa de evangelizar e educar a nação. Como descreve Bastian, "a escola nunca esteve dissociada do templo e se construiu, em geral, ao lado deste último quando se constituía em um local a parte. Em alguns casos, o templo era utilizado para o culto e para o ensino" (1994, p.129). Sarat e Furtado em seus estudos sobre a presença protestante em Mato Grosso descrevem que "havia também interesses expansionistas, mercantilistas e colonizadores envolvidos nessas missões", mas ressaltam que "os missionários que as representavam vinham convictos de sua missão sob a égide de um projeto educacional e salvacionista" (SARAT e FURTADO, 2016, p. 275).

Alexis de Tocqueville, em A democracia na América, concentra suas investigações nas questões sócio-políticas na tentativa de demonstrar que o desenvolvimento da democracia norte-americana é devedor principalmente dos hábitos, dos costumes e da religião herdados do sistema moral dos seus fundadores, os imigrantes puritanos. Segundo Vieira (2006, p. 62), embora priorize estes aspectos em sua teoria dos determinantes sociais, Tocqueville considera que os fatores ligados à situação histórica particular e às leis foram fundamentais na formação da sociedade americana, ainda que de modo secundário, estabelecendo uma hierarquia entre estes três tipos de causas. Para ele "as causas físicas [geográficas e históricas] contribuem menos que as leis, e as leis menos que os costumes [a moral e religião]" (TOCQUEVILLE, 2005, p. 363).

Tendo como parâmetro o apego da sociedade francesa à liberdade e menos às questões relativas à fé, considera que a desestruturação religiosa em uma sociedade instaura a dúvida, que leva a cada qual se habituar a ter "noções variáveis e confusas sobre as coisas que mais interessam a seus semelhantes e a si mesmo; defende mal suas opiniões ou as abandona; e, como sente-se incapaz de resolver por si só os demais problemas que o destino humano apresenta, covardemente abstém-se de pensar neles" (TOCQUEVILLE, 2005, p. 405).

Ao abandoná-las permite, sem resistência, que usurpem sua liberdade. Para o sociólogo francês, as instituições democráticas assumem um papel importante na preservação dos aspectos da liberdade e da democracia. Assim também a instrução escolar, em uma sociedade democrática, é condição necessária para assegurar uma boa formação de seus cidadãos à medida que as "condições sociais se nivelam e cada um torna-se tão forte e capaz quanto qualquer outro, para pensar e julgar por si mesmo acerca de todas as questões 
que lhe dizem respeito, mais vale que todos possam dispor de luzes e costumes que os auxiliem a bem julgar e bem agir" (REIS, 2009, p. 105).

Embora parta de uma premissa um tanto genética de que os anglos americanos já chegaram civilizados às novas possessões, pois eram portadores de um conhecimento adquirido, "resultado de dezoito séculos de trabalho e de experiência" (TOCQUEVILLE, 2005, p. 357), para Tocqueville a educação escolar na América não se presta simplesmente a ensinar a ler e a escrever como condição para sua participação como cidadão, como era visto na Europa de um modo geral, mas se volta para atender a uma tríplice dimensão, primeiro constituída por seu caráter pragmático, segundo por possibilitar ao indivíduo conhecimentos que lhe assegurem uma percepção da sua cidadania e, terceiro por estar à serviço da república democratica. "Nos Estados Unidos, o conjunto da educação dos homens está dirigido para a política; na Europa, sua finalidade principal é preparar para a vida privada" (TOCQUEVILLE, 2005, p, 358).

Guardada as devidas proporções, já que não podemos afirmar simplesmente que os mesmos traços constitutivos do protestantismo norte-americano possam ser encontrados, de igual maneira no protestantismo que mais de dois séculos depois chegaria ao Brasil, esta mesma perspectiva religiosa e educacional fora percebida como inovadora e, a implantação da educação norte-americana, passou a ser vista como modelo ideal de mudança do sistema político em toda a América Latina. E, foram os missionários protestantes quem melhor atenderam às expectativas de mudança de determinados setores liberais da sociedade que haviam se interessado pelo protestantismo, tanto por sua afinidade eletiva com $o$ liberalismo radical, como pelas obras civilizadoras que suas associações punham a disposição de seus membros (BASTIAN, 1994, p. 148). Mais afeito as questões práticas do que propriamente teóricas, Tocqueville percebeu que o espírito americano, de um modo geral, não se prendia as ideias gerais e pouco valorizava as grandes descobertas dos sistemas teóricos, a valorização estava mais voltada para uma educação pragmática, para a indústria e a capacitação profissional do indivíduo. Interessava a descoberta e a utilização de métodos novos que permitissem, de forma mais ágil, chegar ao enriquecimento, pois o maquinário agilizava o trabalho. $\mathrm{O}$ caráter instrumental da educação protestante, diminuía custos na produção e satisfazia as necessidades imediatas por uma reforma dos comportamentos das sociedades em transição. Segundo Carvalho (1998, p.109), no Brasil, "o dândi afrancesado ao estilo belle-époque começa a sentir a competição do sportsman cultor do físico, dinâmico, empreendedor" proporcionado por um tipo de educação mais apropriada para cumprir as exigências do futuro.

Este contexto de concepções liberais e pragmáticas permitiu conceber mudanças sociais e educacionais, a partir de um processo civilizador, que se estabeleceria por meio da educação dos modos e dos comportamentos sociais. Processo civilizador, entendido, conforme Elias (1993, 1994), como um período de longa duração, no qual ocorreram mudanças estruturais na sociedade, a partir de fatores como "sociogênese" e "psicogênese". Ou seja, as mudanças coletivas partem da sociogênese, especialmente na constituição e aceitação nos grupos sociais das formas de regulação e controle dos comportamentos, antes pautados pelas instâncias primárias das reações humanas. À medida que tais instâncias passam a ser reguladas pelas mudanças sociais e, vão sendo internalizadas pelos indivíduos (psicogênese), estas controlam seus comportamentos, seus modos, seu habitus, portanto, permitem sua inserção no grupo social do qual o indivíduo faz parte. O grupo é fundamental no processo de regulação e controle das emoções e ações individuais e coletivas pois, nele se constitui, se estabelece, se exerce e se controla os padrões e normas de comportamentos impostos e esperados socialmente. 
Tal aspecto é relevante pois a proposta da sociedade do século XIX seria viver um novo momento, no qual a educação estaria no centro da regulação dos costumes sociais sendo responsável para elevar o país ao lugar de nação civilizada. Segundo Veiga, "a difusão da escolarização como categoria de atividade social foi fundamental para os processos de alteração da sociabilidade em curso, ao longo do século XIX e no início do século XX", pondera Cynthia G. Veiga, "bem como para as mudanças dos mecanismos de produção das distinções sociais” (VEIGA, 2002, p. 99).

O processo educativo que chegou com a vinda de grupos de imigrantes norteamericanos, especialmente do protestantismo de missão também foi muito bem recebido, em toda a América Latina, pois as missões pautadas em propostas educacionais, faziam coro com as mudanças almejadas pelos grupos políticos e dirigentes locais. Assim, a receptividade destes projetos, além de favorecer a renovação em diferentes frentes tinha uma proposta educativa que propugnavam civilizar o nativo, o homem simples, conforme Faria Filho e Pineau (2009, p. 91) apontam: "El ciudadano 'criollo' por ser formado presuponía la adhesión a ciertas prácticas culturales más modernas asociadas a la creación de sujetos con un nivel de individualidad y autorregulación mayor que lo presentado por los sujetos políticos preexistentes".

É possível perceber nesta dinâmica um processo de civilidade dos comportamentos mediados por um alto grau de regulação e controle dos grupos sociais, à medida que ofertavam novos costumes as populações. A educação ensinada nas escolas tinha esse caráter de mudança de valores com projetos de educação formal que também garantiam formas de regulação social atendendo a uma expectativa dos setores mais liberais da sociedade "e um reconhecimento interessado, as vezes entusiasta, por parte dos governos ou de autoridades políticas locais" (BASTIAN, 1994, p. 129), como fica claro em estudos realizados anteriormente por Vieira $(2006,2016)$.

Dando ênfase a esta questão, Buriti e Barros ressaltam que a escola funcionava como espaço institucional de regras e normas, a serem aprendidas desde a mais tenra idade, pois os objetivos pedagógicos eram "formar cidadãos individualizados, civilizados, treinados nos sentidos e corpos, e colocados à disposição da cidade, do estado, da pátria" (BURITI; BARROS, 2016, p. 35). Cuidavam integralmente do indivíduo, não só na perspectiva religiosa, mas também introduziram medidas higiênicas - ao modo norteamericano - influenciando a cultura local, os modos e os costumes das populações.

As escolas abertas tinham uma proposta educacional que expressavam nas práticas pedagógicas o ideário de um mundo civilizado. Fundavam-se na adoção de uma pedagogia moderna para a época, com ênfase em disciplinas como "línguas antigas e modernas (latim, português, francês, inglês), gramática, caligrafia, aritmética, matemática, álgebra, geometria, astronomia, cosmografia, geografia, história universal, história do Brasil, história sagrada, literatura, ciências naturais (botânica, física, química, zoologia, mineralogia), lições de coisas, artes (desenho, piano, costura à mão e bordado) e ginástica" (MESQUIDA, 1994, p. 156). Importava um ensino útil, prático e de resultados concretos. Os conteúdos apontavam para um conhecimento que poderia ser usado na resolução de problemas podendo contribuir com a mudança social, logo com a manutenção da nova república.

A escola deveria introduzir métodos inovadores que elevassem o conhecimento aos níveis mais altos de preparação para a vida e o trabalho. Ao servirem-se de métodos pedagógicos fundados nos preceitos teóricos advindos principalmente do suíço Johann Heinrich Pestalozzi (1746-1827), do alemão Friedrich W. A. Froebel (1782-1852) e do 
norte-americano Horace Mann (1796-1859) os métodos escolares norte-americanos começaram definitivamente a influenciar o ensino público e particular da América Latina. A ênfase colocada sobre o estudo das ciências exatas, das artes e das línguas e, sobretudo, das ciências naturais, sem, contudo, esquecer-se das humanidades provocaram reações de entusiasmo do grupo que confiava na educação protestante.

O método pedagógico empregado em seus colégios chamava-se de intuitivo, porque dava importância central à intuição, à observação e à experiência através dos sentidos ou, como também ficou conhecido, lições de coisas. Sinteticamente falando, o método intuitivo "pretende direcionar o desenvolvimento da criança de modo que a observação gere o raciocínio e o trabalho prepare o futuro produtor, tornando indissociável pensar e construir" (Cf. VALDEMARIN, 2006, p. 93). Tais conteúdos renovaram a escola do período, principalmente por se contrapor às escolas católicas e públicas do Império, logo, tiveram grande aceitação, principalmente entre os reformadores do sistema político, que almejando consolidar a República, tinham interesse no tipo de educação que serviria as elites republicanas e que inscreveria o país no movimento civilizatório orquestrado pelas nações mais desenvolvidas.

\section{Educação e civilidade}

Os protestantes e os entusiastas republicanos, reformadores da educação inspiravam-se nestes modelos norte-americanos e apostaram em investimentos no desenvolvimento de novos saberes e técnicas de aprendizagem. Tal tecnologia estava aliada a concepção de uma educação civilizatória, que permitia o emprego destas perspectivas provocando mudanças nos costumes e avançando na formação da sociedade, pois "o conceito de civilização se revela no nível da tecnologia, ao tipo de maneiras, ao desenvolvimento de conhecimentos científicos, as ideias e os costumes" (ELIAS, 1994, p. 23).

Considerando que as mudanças sociais são processuais e estão pautadas em transformações que passam pelo indivíduo e seu grupo social, podemos dizer que o processo educacional permitiu o acesso ao conhecimento veiculado na escola, nos processos formativos da educação do indivíduo e, portanto, tal processo civilizatório reverbera em todos os segmentos da organização humana. Para Elias (1994) a civilização referia-se também aos modos como os grupos se organizavam, suas formas de morar, se alimentar, procriar, controlar seus corpos, suas emoções, seus desejos, seus sistemas de punição, regulação, religião, enfim, todas as dimensões da vida humana.

A educação, é assim, uma das formas de controle social à medida que ela propugna determinadas visões de mundo, portanto, retomando o aspecto de uma educação voltada para a dimensão da formação política, que se expressava na obtenção de conhecimentos sobre as leis do país, a religião e a história da nação, bem como as formas de organização política e social. Podemos dizer que tais elementos deveriam ser aprendidos desde cedo pois, estes elementos deveriam levar à formação de um modelo de serviço, no qual o indivíduo aprendesse a servir a nação, a Deus e à República. Modelo que se espalhou por todos os lugares por onde suas missões alcançaram.

Nessa direção podemos dizer que as escolas protestantes norte-americanas fazem parte de uma cultura e tradição que teve início desde o século XVI, quando em 1642 os pais fundadores da pátria, iniciaram um processo de escolarização que se transformaria em um sistema de escolas públicas asseguradas a todas as crianças. Os registros informam que 
"a colonia de Massachusetts aprovou uma lei atribuindo a educação dos filhos aos seus pais. Em 1647, contudo, esse compromisso com a educação foi estendido com a aprovação de outra lei mais radical que exigia que todas as cidades fornecessem escolas e professores para suas crianças" (JOHN, apud MARTINS, 2008, p. 63). Em um prazo de quarenta anos todas as colônias americanas acompanhando o modelo de Massachusetts criaram escolas, ou seja:

Até o fim do século dezessete tinha-se como certo que os cidadãos das colônias inglesas deveriam ser educados; a alfabetização devia ser encorajada para que as crianças pudessem entrar em contato com as verdades religiosas, para que elas pudessem ser preparadas para lidar com as incertezas da vida colonial e de fronteira, e para que algumas desenvolvessem os talentos necessários para conduzir os negócios políticos, econômicos e religiosos das colônias (JOHN apud MARTINS, 2008, p. 63).

A promulgação e aplicação desta lei na colônia de Massachusetts serviu de inspiração para as demais colônias, tanto ao norte quanto nas demais possessões dos Estados Unidos, de tal forma a contribuir para o surgimento de escolas públicas em diversos lugares do país alcançando inúmeras colônias e sendo o gérmen que viria a dar originem as universidades mais prestigiadas do país ao longo do século XVII e XVIII ${ }^{9}$. Thomas Jefferson (1743-1826) teria aconselhado sabiamente que, "tendo conquistado suas liberdades e estabelecido sua República, os americanos fariam bem em perpetuar ambas através da educação" (CREMIN, 1963, p. 40), pois este deveria ser o fim último da educação: "preparar os jovens para inteligente cidadania e participação nos negócios do governo" (KANDEL, 1963, p. 22).

Tais eventos históricos apontam para um caminho em direção do processo de formação das instituições educativas no Brasil, e, os modos como diferentes modelos foram se organizando e se adequando às novas realidades. Entretanto é inegável afirmar que estas instituições nacionais sofreram influências fundamentais das concepções pragmáticas, patrióticas, liberais e puritanas, amalgamadas nas bases do protestantismo norte-americano.

Neste contexto, é possível perceber que o diálogo entre as propostas de educação protestante e a instauração de um modelo civilizador para a educação brasileiras fora construído sob pilares de uma proposta direcionada para as mudanças estruturais da sociedade. Essa ideia converge com um período no qual a busca pela instauração de novos padrões de conduta e civilidade era o principal fundamento do mundo moderno. Portanto, formar uma nova nação culta, civilizada e preparada para lidar com o progresso fazia parte do ideário deste período histórico.

Outro aspecto interessante é que o projeto civilizatório se expressava em mudanças de costumes, comportamentos e modos de se relacionar uns com os outros, considerando que as mudanças são sociais e históricas, podemos dizer, com Elias (1994b, p. 47) que a história se constitui em um "sistema de pressões de pessoas vivas exercidas sobre pessoas vivas", ou seja, homens e mulheres imbuídos de uma formação, na qual acreditavam que poderiam mudar e influenciar o outro atuando socialmente à medida que pudessem expandir tais conhecimentos e ensinar, instruir, civilizar o outro. Estes indivíduos imbuídos

\footnotetext{
${ }^{9}$ Harvard foi a primeira instituição de ensino superior a ser criada nos Estados Unidos no ano de 1636.

Chamada de New College só se tornou universidade em 1780.
} 
dessa concepção, representantes de um poder simbólico construído e dirigido por um "governo divino", mas também terreno, os levava a tal crença, pois tinham a convicção de que suas instituições eram melhores que as demais. Ao falar da educação nas escolas, D Jair informa enfaticamente: "minha irmã se formou em 1924. Um tempo de colégio genuinamente escola. Aprendeu bastante, foi uma esplêndida aluna e uma esplêndida professora A formação e a fé estavam indissociáveis.

Além da atenção que as escolas protestantes deram a educação das mulheres, a contribuição norte-americana também foi marcante em outros aspectos da vida econômica, social e cultural da nação, conforme apontado em estudos anteriores conduzidos por Mesquida (1994) e os irmãos Dawsey (2005) e Martins (2009). Várias foram as inovações que os norte-americanos, especialmente os que vieram para o Oeste paulista, trouxeram em suas bagagens e que influenciou substancialmente no desenvolvimento econômico e tecnológico do Brasil.

Entretanto, os irmãos Dawsey chamam a atenção para o fato de que "apesar de alguns pesquisadores terem atribuído tais progressos aos emigrantes, não devemos exagerar a importância dos colonizadores sulistas no desenvolvimento econômico e tecnológico do Brasil” (2005, p. 38), pois estas mudanças estavam circunscritas no quadro de referências mais amplo do desenvolvimento econômico mundial. De qualquer modo, podemos afirmar que tais inovações foram fundantes na mudança dos costumes e dos comportamentos influenciando novos modos de produção da vida e do trabalho.

Estas contribuições constituíam inovações, mas, demandavam uma educação que permitisse aos indivíduos aprender a relacionar-se com o novo modo de produção da vida que estava sendo proposta. Segundo Elias (1994b), as mudanças sociais não partem de perspectivas individuais e nem coletivas separadamente, mas de um conjunto no qual estes elementos estão intrinsicamente ligados, constituem uma rede na qual se estabelece as regras, as normas e os modos de regulação social dos grupos. Portanto, sabemos que embora os avanços e as contribuições foram relevantes estas propostas atingiam grupos menores, especialmente considerando a educação dos colégios que atendiam as elites.

\section{CONSIDERAÇÕES FINAIS}

Nas três últimas décadas do período Imperial o Brasil recebeu diferentes grupos do chamado protestantismo de missão, ligados ao que chamamos aqui de projeto de expansão norte-americana. Tal diversidade religiosa fomentou o debate entre os grupos locais que defendiam um estado laico e republicano em divergência com os que defendiam a confissão católica em seu vínculo com o estado. Estes protestantes eram portadores de uma religião civil, que de acordo com Tocqueville (2005, p. 357), serviu "poderosamente para a manutenção da república", e que fora capaz de proporcionar as condições necessárias para influenciar "poderosamente" a formação e manutenção de novas sociedades em diversos países da américa latina, tais como Argentina, Brasil, Bolívia, Chile e México dentre outros.

Seus agentes propagadores tinham a consciência de que a função de suas escolas se dava para além dos seus próprios métodos, seus prédios bonitos, seus recursos humanos e materiais. Eram conscientes de que a utilização desses artifícios visava antes estabelecer seu domínio no campo educacional formando a consciência e os valores de uma sociedade cristã, gerando homens e mulheres que pudessem se colocar a serviço dessa mentalidade tanto no campo religioso quanto político, onde quer que atuassem. Concordando com 
pesquisadores como Mesquida (1994) e Vieira (2006) podemos dizer que era uma contra educação, em relação à educação de forte tendência católica dominante. Era uma luta entre dois sistemas opostos. De um lado, tanto no plano religioso como cultural, representado pelo catolicismo, visto como opressor e, ao qual era atribuída a causa da ignorância, da superstição e do atraso do país; do outro, o protestantismo libertador identificado como portador da civilização, através da educação e da ciência, representante do progresso (VIEIRA, 2006, p. 186).

A pedagogia desenvolvida nos colégios protestantes, responsável pelos novos métodos calcados na ideologia liberal que colocava como meta individual o êxito e como a soma destes o progresso da sociedade, veio justamente fornecer o respaldo ideológico para os republicanos que buscavam na educação os pressupostos necessários para a implantação e a preservação de suas ideias.

As iniciativas protestantes quanto a este objetivo foram bastante significativas e se ampliaram durante as duas primeiras décadas do regime republicano. Entretanto, a influência de seus colégios incidiu mais diretamente na organização escolar e nos processos didáticos do que em termos doutrinários, propriamente ditos, segundo constatação tanto de Ribeiro (2003, p. 68) como Mendonça (1984). Educação e religião, no contexto estudado estão de certa forma intrinsecamente ligados. Assim a aceitação dos educadores protestantes abriu também espaço para seus pastores exercerem publicamente a sua fé e, a dirigir sua mensagem evangelizante para as camadas mais pobres da sociedade. Os colégios atenderam as elites que teriam a responsabilidade de influir na configuração social do país, às Igrejas cabia massificar o evangelho formando uma nova cultura religiosa num país católico por tradição.

Terminamos com o registro da fala utilizada inicialmente e, nos permitindo parafraseá-la podemos dizer: "sou de família plenamente protestante" caso, a nossa entrevistada dissesse esta frase, ao invés de indicar a sua própria denominação, certamente teria o mesmo sentido, pois os documentos e registros nos informam que o modo religioso e protestante colocado no modelo norte-americano de educar, deu sentido e, se impregnou na vida, na educação e, na formação daqueles que passaram por esta experiência, se expandindo de modo a fazer parte da história da educação brasileira e a contribuir de forma profícua com esta história e com o processo civilizador empreendido por este grupo.

\section{REFERÊNCIAS}

BASTIAN, Jean-Pierre. Protestantismos y modernidade latino-americana: história de unas minorias religiosas activas em América Latina. México: Fondo de Cultura Económica, 1994.

BURITI, I.; BARROS, M. A. "Onde Deus nos outorga constante instrução": a educação como tática de inserção do Protestantismo no Brasil. In: VIEIRA, C. R. A.; NASCIMENTO, E. F. (Orgs.). Contribuições do Protestantismo para a História da Educação no Brasil e em Portugal. Piracicaba: UNIMEP, 2016 (p. 21-43).

CARVALHO, J. M. Pontos e bordados: escritos de história e política. Belo Horizonte: UFMG, 1998. 
CREMIN, L. A. O futuro da escola comum Americana. In: BEREDAY, G. Z. F.;

VOLPICELLI, L. (Orgs.). Educação pública nos Estados Unidos. São Paulo: Instituto Brasileiro de Difusão Cultural S.A., 1963, p. 40-56.

DAWSEY, J. M.; DAWSEY, C. B. As contribuições dos confederados para a agricultura, a religião e a educação brasileiras. In: DAWSEY, J. C.; DAWSEY, J. M.; DAWSEY, C. B (Orgs.). Americans, imigrantes do velho sul no Brasil. Piracicaba: UNIMEP, 2005, p. 137160.

ELIAS, N. A Sociedade dos Indivíduos. Rio de Janeiro: Jorge Zahar Ed; 1994b.

ELIAS, N. O processo civilizador: uma história dos costumes. V 1. Rio de Janeiro: Jorge Zahar Ed; 1994.

ELIAS, N. O processo civilizador: formação do estado e civilização. V 2. Rio de Janeiro: Jorge Zahar Ed; 1994.

FARIA FILHO, L. M.; PINEAU, P. A educação e a questão da construção de identidades modernas no século XX: os casos da Argentina e do Brasil. In: VIDAL, D.; ASCOLANI, A. (Orgs.). Reformas Educativas no Brasil e na Argentina: ensaios de história comparada da educação (1820-2000). São Paulo: Cortez; 2009 (p. 87-114).

KANDEL, I. L. Teorias filosóficas de educação Americana. In: BEREDAY, G. Z. F.; VOLPICELLI, L. (Orgs.). Educação pública nos Estados Unidos. São Paulo: Instituto Brasileiro de Difusão Cultural S.A., 1963, p. 22-39.

MARTINS, L. C. A relação entre protestantismo e sociedade brasileira no final do século XIX frente aos temas da educação e escravidão. 2008. Tese (Doutorado em Educação) Universidade Metodista de Piracicaba, Piracicaba, São Paulo, 2008.

MARTINS, L. C. A dimensão civilizatória da presença americana no Brasil: Tecnologia, Educação e Religião. Revista Cesumar - Ciências Humanas e Sociais Aplicadas v. 14, n. 2, jul./dez. 2009, p. 285-301.

MENDONÇA, A. G. O celeste porvir: a inserção do protestantismo no Brasil. 3ed. São Paulo: Edusp; 2008.

MESQUIDA, P. Um destino manifesto: a presença de mulheres missionárias metodistas na educação brasileira. In: VIEIRA, C. R. A; NASCIMENTO, E. F. (Orgs.). Contribuições do Protestantismo para a História da Educação no Brasil e em Portugal. Piracicaba: Editora Unimep; 2016 (p. 185-206).

MESQUIDA, P. Hegemonia norte-americana e educação protestante no Brasil. São Bernardo do Campo, SP: EDITEO; Juiz de Fora, MG: Editora da UFJF; 1994.

MOOG, Vianna. Bandeirantes e pioneiros: paralelos entre duas culturas. Rio de Janeiro: Graphia, 2000.

REILY, D. A. História documental do protestantismo no Brasil. São Paulo, SP: ASTE; 1984.

REIS, H. E. A democracia como processo: política e educação no pensamento de Tocqueville. Contexto \& Educação, UNIJUÍ, 24, n. 82, jul./dez. 2009, p. 97 - 110.

SARAT, M. e FURTADO, A. História da Educação Protestante em Mato Grossos do Sul: aproximações com a pesquisa In: VIEIRA, C. R. A.; NASCIMENTO, E. F. (Orgs.). 
Contribuições do Protestantismo para a História da Educação no Brasil e em Portugal, Piracicaba: UNIMEP, 2016, p. 265-290.

TOCQUEVILLE, A. A Democracia na América. Trad. Educardo Brandão, 2. ed. Martins Fontes. São Paulo, 2005.

VALDEMARIN, V. T. O método intuitivo: os sentidos como janelas e portas que se abrem para um mundo interpretado. In: SAVIANNI, D.; ALMEIDA, J. S.; SOUZA, R. F.;

VALDEMARIN, V. T. (Orgs.). O legado educacional do século XIX. 2. ed. ver. e ampl. Campinas: Autores Associados, 2006, p. 85-132.

VEIGA, C. A escolarização como projeto de civilização. Revista Brasileira de Educação, v 21, p. 90-103. 2002.

VIEIRA, C. R. A. Protestantismo e educação: A presença liberal norte americana na reforma Caetano de Campos - 1890. 205p. Tese (Doutorado em Educação) - Universidade Metodista de Piracicaba, Piracicaba, São Paulo, 2006.

IEIRA, C. R. V. Notícias da educação metodista no Oeste paulista: o Colégio Piracicabano. In: VIEIRA, C. R. A.; NASCIMENTO, E. F. (Orgs.). Contribuições do Protestantismo para a História da Educação no Brasil e em Portugal. Piracicaba: UNIMEP; 2016, p. 133155.

WEBER, M. Ensaios de sociologia. Rio de Janeiro: Editora Guanabara [s.d.].

Recebido 08/10/2016

Aprovado 20/12/2016 